\title{
Tricky brucellosis
}

\author{
Mojtaba Hedayat Yaghoobi, ${ }^{1}$ Bahaoddin Siroos, ${ }^{2}$ Morteza Foroumandi, ${ }^{3}$ \\ Mehrnaz Asadi Gharabaghi ${ }^{4}$
}

${ }^{1}$ Department of Infectious Diseases, Tehran University of Medical Sciences, Tehran, Islamic Republic of Iran

${ }^{2}$ Iranian Center of Neurological Research, Tehran University of Medical Sciences, Tehran, Islamic Republic of Iran

${ }^{3}$ Department of Medicine, Tehran University of Medical

Sciences, Tehran, Islamic Republic of Iran

${ }^{4}$ Department of Pulmonary Medicine, Tehran University of Medical Sciences, Tehran, Islamic Republic of Iran

\section{Correspondence to}

Dr Mehrnaz Asadi Gharabaghi, asadi_m@tums.ac.ir
To cite: Hedayat Yaghoobi M, Siroos B, Foroumandi $\mathrm{M}$, et al. BMJ Case Rep Published online: [please include Day Month Year] doi:10.1136/bcr-2013009522

\section{SUMMARY}

We present a 23-year-old woman who was admitted due to fever, palpitation, musculoskeletal pain and a transient bout of sudden-onset left-sided hemiparesis. She had also myopericarditis according to echocardiography findings. After comprehensive diagnostic work-up for infectious and immunologic disorders, brucellosis was confirmed by bone marrow aspiration culture. She received doxycycline, rifampin and trimethoprim-sulfamethoxazole for 3 months. The treatment was continued with doxycycline and rifampin for another 6 months. By the end of treatment, she recovered completely with no evidence of persistent neurological or cardiac complications.

\section{BACKGROUND}

Brucellosis is believed to be an ancient disease described more than 2000 years ago by the Romans. ${ }^{1}$ It is a multisystem infection with a broad spectrum of clinical presentations. However, central nervous system (CNS) or cardiovascular involvement is very uncommon. ${ }^{2}$ Here we present a case of brucellosis with fever, palpitation, musculoskeletal pain, transient left-sided hemiparesis and myopericarditis.

\section{CASE PRESENTATION}

A 23-year-old woman admitted to hospital owing to a bout of fever, chills and sudden-onset left-side hemiparesis. She also complained of generalised musculoskeletal pain, palpitation, malaise, headache and arthralgia for almost 1 month. She had no history of photosensitivity, malar rash or oral aphthous ulcers. She had $5 \mathrm{~kg}$ weight loss and secondary amenorrhoea for the last 3 months. She was single, non-smoker and reported no illicit drug use or unsafe sex.

MRI of the brain showed high signal intensity areas, regarding the lesions and patient's history, CNS vasculitis was probable. She was started on $1 \mathrm{~g}$ of methylprednisolone intravenously for 3 days with dramatic improvement of neurological symptoms within $24 \mathrm{~h}$ of the first dose. She was then referred to our hospital for further evaluation of collagen vascular disease or systemic vasculitis syndromes.

\section{INVESTIGATIONS}

On clinical examination, she appeared ill with fever, $38^{\circ} \mathrm{C}$ and tachycardia, $120 / \mathrm{min}$. Except facial butterfly rash and painless ulcers in mouth, the rest of systemic examination was normal. Blood tests showed white cell count, 4100/ $\mu$ l (lymphocyte, $680 / \mu \mathrm{l}) ; \mathrm{Hb}, 11 \mathrm{~g} / \mathrm{dl}$; platelet, $325000 / \mu \mathrm{l}$ and erythrocyte sedimentation rate (ESR), $57 \mathrm{~mm} /$ hour.
Liver and renal function assays were normal. Tests of rheumatoid factor, antinuclear antibody (ANA), antineutrophilic cytoplasmic antibody, Wright agglutination, Coombs Wright test, Brucella antibody, antileishmanial antibody, borreliosis and blood cultures were negative. Chest imaging was normal. ECG showed sinus tachycardia (figure 1). Echocardiography revealed mild pericardial effusion, moderate left ventricular systolic dysfunction (ejection fraction; 35\%), hypokinesis in the inferoseptal and inferior left ventricular walls suggestive of myopericarditis. There was no evidence of HIV, Hepatitis C virus (HCV), Ebstein Barr Virus (EBV) and cytomegalovirus (CMV) infection based on viral and immunologic assays. On admission to our hospital, she had fully recovered from hemiparesis and the whole neurological examination was normal. MRI of the brain was once again normal, albeit she had been treated with a 3 day course of high-dose steroid for suspicious CNS vasculitis a week before.

According to constellation of fever, facial rash, mouth ulcers, myopericarditis, lymphopenia and history of neurological symptoms resolved by highdose steroid, the probable diagnosis was systemic lupus erythematosis (SLE) but tests of ANA, anti-dsDNA, anti-SSa, anti-SSb antibodies and total complement activity were all normal. She was also negative for anticardiolipin and $\mathrm{B}_{2}$ glycoprotein antibodies. Owing to persistent fever and bone pain, bone marrow aspiration biopsy was performed. There was no evidence of haematological malignancy or haemophagocytic syndrome; but surprisingly Brucella species was isolated from bone marrow aspirate cultures (figures 2 and $3 \mathrm{~A}, \mathrm{~B}$ ).

\section{DIFFERENTIAL DIAGNOSIS}

SLE, acute leukaemia, brucellosis were probable diagnoses.

\section{TREATMENT}

In Iranian patients, Brucella melitensis causes the disease in majority of cases, so when Brucella species was isolated from non-specific culture media (eg, blood agar) or enriched media (chocolate agar) and identified based on colony feature, biochemical reactions and results of Gram stain smears, further studies such as microbial DNA amplification tests are not performed as they are expensive and do not affect the initial therapeutic plan. Therefore, she was started on doxycycline (100 mg twice daily), rifampin (600 mg daily) and trimethoprim-sulfamethoxazole (TMP-SMZ) (800/ 160 twice daily) for 3 months. 


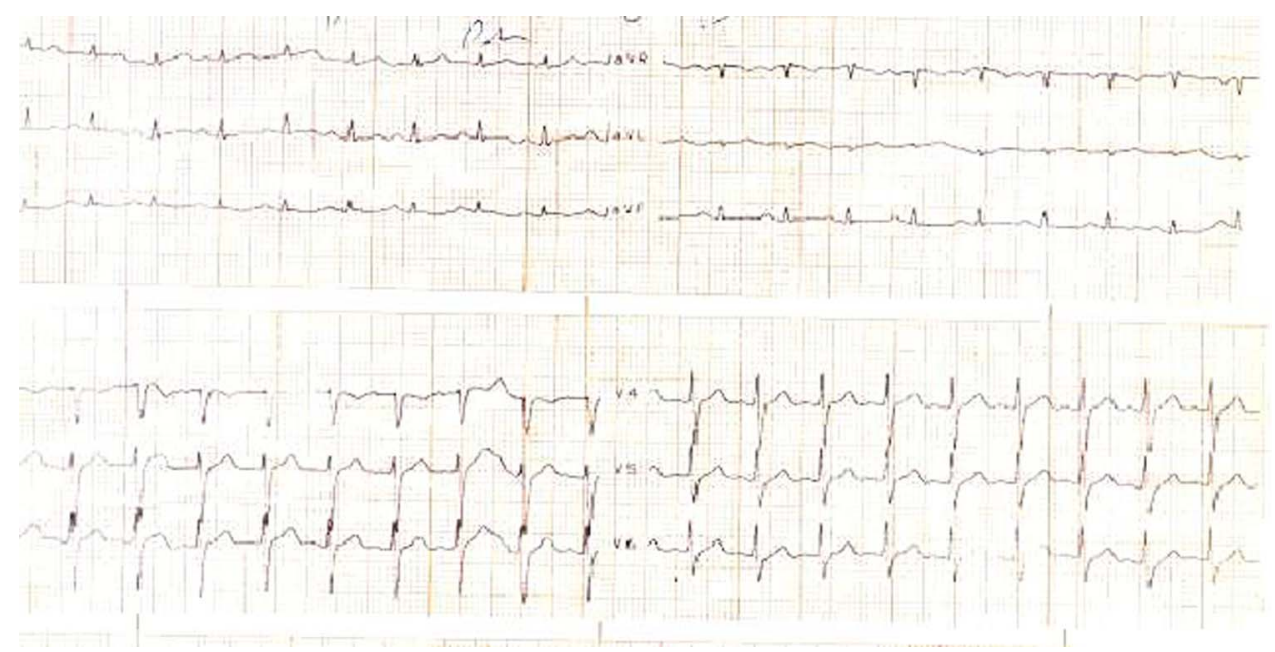

Figure 1 ECG showing sinus tachycardia.

\section{OUTCOME AND FOLLOW-UP}

She improved gradually with treatment. Nonetheless, because of persistent bone pain, treatment was continued for another 6 months with doxycycline and rifampin. Metabolic bone tests including calcium, phosphorus, vitamin D and parathyroid hormone were normal. Whole-body bone scintigraphy and repeated bone marrow aspiration showed no sign of haematological disease. No bacteria grew from marrow cultures by the end of treatment. Repeated sero-immunological assays for brucellosis and SLE were negative and ESR was $12 \mathrm{~mm} / \mathrm{h}$. Six months later, she fully recovered from her symptoms except for mild fatigue.

By the end of treatment, transthoracic echocardiography showed normal left ventricular function with $65 \%$ ejection fraction. No neurological deficit recurred during treatment and thereafter, so follow-up brain imaging was not done.

\section{DISCUSSION}

Brucellosis is caused by intracellular Gram negative bacteria called Brucella. ${ }^{1}{ }^{3}$ Iran is an endemic area for brucellosis. ${ }^{4}$ Human brucellosis has a low mortality rate $(<5 \%)$ mainly due to endocarditis. However, it may lead to severe chronic disease with high mortality. ${ }^{5}$ Clinical manifestations of brucellosis are variable. It commonly presents with fever and musculoskeletal symptoms. However, it may present in a tricky way making its diagnosis difficult with cardiac and neurological manifestations

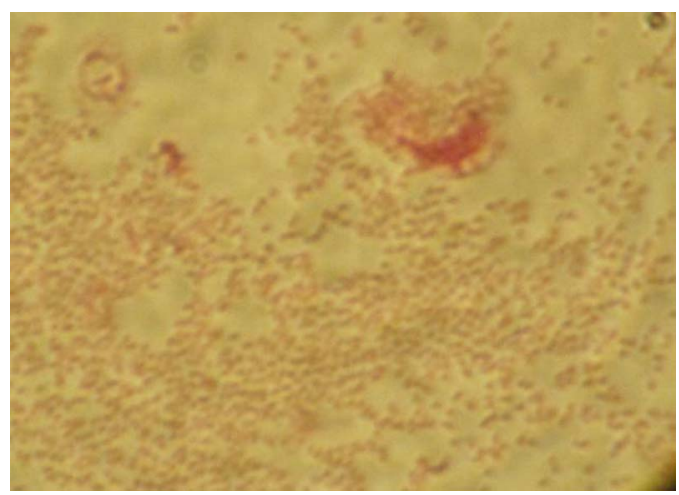

Figure 2 Gram stain smear of bone marrow aspirate showing abundant small Gram-negative coccobacilli. to be very uncommon. Direct involvement of the nervous system occurs in less than $5 \%$ of the cases. Various complications including meningoencephalitis, brain abscess, epidural abscess, myelitis, demyelinating and meningovascular syndromes have been reported in brucellosis. ${ }^{6} 7$ Brucellosis-related vasculitis, an immune-mediated phenomenon can involve all blood vessels including CNS vasculature. Moreover, brucellosis may very rarely present as a cerebral vasculopathy. ${ }^{8}$ Cardiac complications of brucellosis are uncommon, found in less than $2 \%$ of patients with endocarditis as the most common and the main cause of mortality. ${ }^{9}$ It usually involves the aortic valve and often requires an immediate valve replacement surgery. ${ }^{10}$ Isolated pericardial and myocardial involvement in the absence of endocarditis is not common and very rarely reported in brucellosis cases. ${ }^{11}$ Cardiac damage mechanism is not clearly known; however, it may be due to the direct invasion of the microorganism (confirmed by isolation from pericardial fluid) or a damage produced by immune complex deposition. ${ }^{13}$ In the absence of pericardial synthesis, diagnosis is based on the symptoms, serological tests and blood culture along with other possible
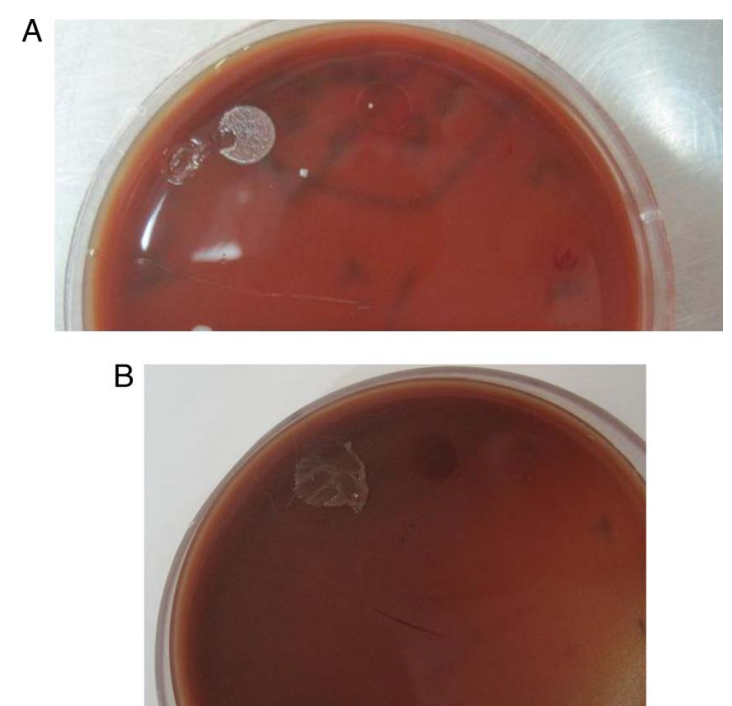

Figure 3 (A and B) Blood agar and chocolate agar culture media, respectively, showing isolation of Brucella species from bone marrow aspirate. 
diagnoses. ${ }^{14}$ Brucella myopericarditis has a favourable course with appropriate treatment. Heart failure with a favourable course has also been reported. Although it is uncommon, brucellosis should be considered as a newly emerged cause of heart failure, especially in endemic regions though it is curable with appropriate antibiotic therapy, obviating the need for unnecessary cardiological interventions. ${ }^{15} \mathrm{~A}$ combination of medical history, clinical examination, haematological and biochemical tests, imaging studies, microbiological assays and brucella-specific molecular and serological tests are needed to make timely diagnosis. Serological evaluations are the most common tests used for diagnosis. Serum agglutination test detects brucella antibody. ELISA is a test of choice for chronic, focal and complicated brucella cases, especially when other tests are negative and there is high clinical suspicion of brucellosis. Positive culture makes definitive diagnosis, considered as the gold standard for laboratory diagnosis of brucellosis. ${ }^{16} \mathrm{~A}$ few patients may have positive culture results while their serology assay is negative. Bone marrow culture yields $15-20 \%$ higher diagnostic rate compared with peripheral blood culture. ${ }^{17}$ In our patient, serologic tests of brucellosis were repeatedly negative. But Brucella spp. grew on bone marrow culture.

Antimicrobial therapy shortens the disease duration, improves the symptoms and decreases the incidence of complications and relapse rate. Various drugs can be used against Brucella. Treating complications such as meningitis or endocarditis is difficult and optimal drug treatment is not definite. Doxycycline has been used successfully with TMP-SMZ and rifampin for treatment of meningitis and endocarditis. ${ }^{18}$

In conclusion, it seems prudent to consider brucellosis when confronting patients with neurological or cardiac diseases of undetermined aetiology, especially in regions with high prevalence of brucellosis. Timely diagnosis and treatment need combination of the patient's history, clinical examination, serological testing and occasionally blood and bone marrow cultures.

\section{Learning points}

- Brucellosis must be considered in evaluation of patients with undetermined neurological or cardiac diseases, especially in endemic regions.

- Brucella may be isolated from marrow or blood aspirates even though serological or immunological tests are negative.

- Brucellosis may mimic systemic lupus erythematosis (SLE).

- The differential diagnosis of infectious myopericarditis includes Brucellosis.
Acknowledgements We acknowledge Mehrnoush Asadi Gharabaghi, as a pharmacist consultant who contributed to patient management and preparation of this manuscript.

Contributors MAG was the physician who managed the patient. BS, MHY and MF were consultant physicians.

Competing interests None.

\section{Patient consent Obtained.}

Provenance and peer review Not commissioned; externally peer reviewed.

\section{REFERENCES}

1 Greenfield RA, Drevets DA, Machado LJ, et al. Bacterial pathogens as biological weapons and agents of bioterrorism. Am J Med Sci2002;323:299-315.

2 Reguera JM, Alarcon A, Miralles F, et al. Brucella endocarditis:clinical, diagnostic, and therapeutic approach. Eur J Clin Microbiol Infect Dis 2003;22:647-50.

3 Sohn AH, Probert WS, Glaser CA, et al. Human neurobrucellosis with intracranial granuloma caused by a marine mammal Brucella spp. Emerg Infect Dis 2003;9:485-8.

4 Hasanjani Roushan MR, Mohrez M, Smailnejad Ganji SM, et al. Epidemiological features and clinical manifestations in 469 adult patients with brucellosis Babol, Northern Iran. Epidemiol Infect 2004;132:1109-14.

5 Mili N, Auckenthaler R, Nicod LP. Chronic brucella empyema. Chest 1993;103:620-1.

6 Mclean DR, Russell N, Khan MY. Neurobrucellosis: clinical and therapeutic features. Clin Infect Dis 1992;15:582-5.

7 Haji-Abdolbaghi M, Rasool-Nejad M, Jafari S, et al. Clinical and laboratory findings in neurobrucellosis: review of 31 cases. Arch Iranian Med 2008;11:21-5.

8 Adaleti I, Albayram S, Gurses B, et al. Vasuclopathic changes in the cerebral arterial system with neurobrucellosis. Am J Neuroradiol 2006;27:384-6.

9 Colmenero JD, Reguera JM, Martos F, et al. Complications associated with Brucella mellitensis infection: a study of 530 cases. Medicine 1996;75:195-210.

10 Mantur BG, Amarnath SK, Shinde RS. Review of clinical and laboratory features of human brucellosis. Indian J Med Microbiol 2007;25:188-202.

11 Anguita M, Díaz V, Bueno G, et al. Pericarditis brucelósica dos formas diferentes de presentación para una etiología poco frecuente. Rev Esp Cardiol 1991;44:482-4.

12 Chocarro Matínez A, González L, ópez A, Zuazola P, et al. Pericarditis brucelar. An Med Interna (Madrid) 2002;19:50-1.

13 Maisch B, Schonloan U, Crombach M, et al. Cytomegalovirus associated inflammatory heart muscle disease. Scand J Infect Dis Supp/ 1993;88:135-48.

14 Villaverde M, Gurini L, González A, et al. Febrile syndrome: myocarditis and brucellosis. Medicina (Buenos Aires) 1995;55:145-6.

15 Cumali $\mathrm{E}$, Tuba $\mathrm{C}$, Munevver I, et al. A rare complication of brucella infection: myopericarditis and heart failure. Intern Med 2009;48:1773-4.

16 Araj GF. Update on laboratory diagnosis of human brucellosis. Int I Antimicrob Agents 2010;36(Suppl 1):s12-17.

17 Yagupsky P. Detection of brucellae in blood cultures. J Clin Microbiol 1999;37:3437-42.

18 Young EJ. An overview of human brucellosis. Clin Infect Dis 1995;21:283-90.

Copyright 2013 BMJ Publishing Group. All rights reserved. For permission to reuse any of this content visit http://group.bmj.com/group/rights-licensing/permissions.

BMJ Case Report Fellows may re-use this article for personal use and teaching without any further permission.

Become a Fellow of BMJ Case Reports today and you can:

- Submit as many cases as you like

- Enjoy fast sympathetic peer review and rapid publication of accepted articles

- Access all the published articles

- Re-use any of the published material for personal use and teaching without further permission

For information on Institutional Fellowships contact consortiasales@bmjgroup.com

Visit casereports.bmj.com for more articles like this and to become a Fellow 